\title{
NHS contribution to the Ebola epidemic
}

\author{
Catherine Houlihan clinical research fellow, Ron Behrens senior lecturer, David Moore professor \\ of infectious diseases and tropical medicine
}

London School of Hygiene and Tropical Medicine, London, UK

RB and DM are also consultant physicians at the Hospital for Tropical Diseases, London

To control the current Ebola epidemic - the largest recorded, with more than 1500 deaths to date - a global response is needed in terms of finance, equipment, and skilled personnel. ${ }^{12}$ The UK government has shown commitment to the global response through the Department for International Development (DFID), which is convening experts from a variety of fields. Furthermore, WHO, Médecins Sans Frontières, the International Federation of Red Cross, and the King's Fund have made national and international calls for healthcare workers to accept temporary contracts and travel to the affected region on targeted "missions."

We believe that the NHS should allow staff temporary leave to contribute to the global response. Consultant physicians, specialty trainees, and specialist nurses who work in infectious diseases, microbiology, virology, public health, intensive care, and infection control are well placed to offer assistance and should be supported. Part of the preparedness will require adequate training to reduce personal risk and ensure the best possible clinical care in the circumstances. Their experience and new skills would enhance the NHS pool of expertise for similar events in the future. We have anecdotal reports of doctors and nurses being denied leave for these activities, possibly due to lack of peer support or financial and resource pressures. If financial pressures on NHS trusts are a barrier to release of staff, central funding through DFID to NHS trusts might be an option.

According to WHO, the Ebola epidemic in West Africa is now an international public health emergency. ${ }^{3}$ NHS trusts and deaneries must approve and fast track requests from NHS staff who are willing to contribute their time and skills to deal with this crisis.

\section{Competing interests: None declared.}

Full response at: www.bmj.com/content/349/bmj.g5079/rr/763547.

Fletcher TE, Brooks TJG, Beeching NJ. Ebola and other viral haemorrhagic fevers. BMJ 2014;349:g5079. (11 August.)

2 Ansumana R, Bonwitt J, Stenger D, Jacobsen KH. Ebola in Sierra Leone: a call for action Lancet 2014;384:303.

3 WHO. WHO director-general briefs Geneva UN missions on the Ebola outbreak. 2014. www.who.int/dg/speeches/2014/ebola-briefing/en/. 